\title{
ESCOLA MARIA TERESA VILANOVA CASTILHOS - ESCOLA POLIVALENTE: ACERVOS FOTOGRÁFICOS E HISTÓRIA DA EDUCAÇÃO
}

\author{
Maria Augusta Martiarena de Oliveira \\ Instituto Federal de Educação, Ciência e Tecnologia do Rio Grande do Sul \\ martiarena.augusta@gmail.com
}

\begin{abstract}
RESUMO
No bojo do Projeto sobre a história e a memória da Escola Polivalente de Osório-RS, este artigo objetiva discorrer sobre a compreensão do acervo fotográfico como importante elemento constituinte do patrimônio histórico-educativo da instituição objeto de pesquisa, bem como apresentar as possibilidades de estudo da cultura escolar a partir da dos documentos constantes no acervo. Entende-se que o significado de patrimônio históricoeducativo permite que se considere as fotografias escolares como integrantes dessa materialidade escolar. Digitalização e disponibilização online configuram-se em estratégia de preservação. Além disso, realiza-se um trabalho de análise desses documentos, o qual pretende gerar uma série de estudos de diferentes aspectos da cultura escolar.
\end{abstract}

Palavras-chave: Acervos fotográficos. Patrimônio histórico-educativo. Cultura escolar.

\section{MARIA TERESA VILANOVA CASTILHOS SCHOOL - POLIVALENTE SCHOOL: PHOTOGRAPHIC COLLECTION AND HISTORY OF EDUCATION}

\begin{abstract}
In the context of the project about history and memory of the Polivalente School of Osório$\mathrm{RS}$, this article aims to discuss the understanding of the photographic collection as an important element that is part of the historical and educational heritage of the researched institution. Besides that, we intend to present the possibilities of study of school culture on the basis of the documents of the collection. We understand that the meaning of historicaleducational heritage allows the school photographs to be considered as part of this school materiality. Scanning and online availability are found as a preservation strategy. In addition, a work of analysis of these documents is carried out, which intends to generate a series of studies of different aspects of the school culture.
\end{abstract}

Keywords: Photographic collections. Historical educational heritage. School culture.

\section{ESCUELA MARIA TERESA VILANOVA CASTILHOS - ESCUELA POLIVALENTE: FUNDOS FOTOGRÁFICOS E HISTORIA DE LA EDUCACIÓN}

\section{RESUMEN}

En el marco del Proyecto sobre la historia y la memoria de la Escuela Polivalente de OsórioRS, este artículo objetiva discurrir sobre la comprensión del fundo fotográfico como importante elemento del patrimonio histórico-educativo de la institución objeto de investigación, así como presentar las posibilidades de estudio de la cultura escolar a partir de los documentos contenidos en el fundo. Se entiende que el significado de patrimonio histórico-educativo permite considerar las fotografías escolares como integrantes de esa materialidad escolar. La digitalización y la disponibilidad en línea es una estrategia de 
preservación. Además, se realiza un trabajo de análisis de esos documentos, el cual pretende generar una serie de estudios de diferentes aspectos de la cultura escolar.

Palabras clave: Fundos fotográficos. Patrimonio histórico-educativo. Cultura escolar.

\section{ÉCOLE MARIA TERESA VILANOVA CASTILHOS - ÉCOLE POLIVALENTE: RÉALISATIONS PHOTOGRAPHIQUES ET HISTOIRE DE L'ÉDUCATION}

\section{RÉSUMÉ}

Dans la foulée du Projet sur l'histoire et la mémoire de l'Ecole Polivalente d'Osório-RS, cet article a pour but de discuter la compréhension de la collection photographique un élément important du patrimoine historique et éducatif de l'institution objet de recherche et de présenter les possibilités d'étude de la culture scolaire sur la base des documents contenus dans l'acquis. Il est entendu que la signification du patrimoine historique et éducatif permet de considérer les photographies scolaires comme partie de cette matérialité scolaire. La digitalization et la disponibilité en ligne sont configurées dans une stratégie de préservation. En outre, un travail d'analyse de ces documents est réalisé, qui vise à générer une série d'études sur différents aspects de la culture scolaire.

Mots-clés: Collections photographiques. Patrimoine historique-éducatif. Culture scolaire.

\section{INTRODUÇÃO}

Em 2012, deu-se início ao desenvolvimento de uma pesquisa referente à história das instituições educacionais e seus acervos escolares na cidade de Osório, localizada no litoral norte do estado do Rio Grande do Sul (Brasil). Destaca-se que essa cidade emancipou-se no ano de 1857, da cidade de Santo Antônio da Patrulha, um dos municípios mais antigos da região. Nesse momento, chamava-se Conceição do Arroio, nome que foi alterado em 1934, pelo então governador do estado, Flores da Cunha. O município passou a chamar-se Osório, em homenagem ao Marechal Manoel Luís Osório, patrono da Cavalaria nacional, que ali nasceu.

Verificou-se que, mesmo com uma trajetória histórica longa para os padrões nacionais, notadamente para a região sul do Brasil, a qual integrou-se tardiamente, pouco foi estudado sobre a história local e sobre a história das instituições educacionais locais. Sobre este tema, encontrou-se a tese de doutorado de Dóris Bittencourt Almeida, denominada "Memórias da rural: narrativas da experiência educativa de uma escola normal rural pública (1950-1960)", que tinha como objeto a Escola Estadual de Ensino Médio Ildefonso Simões Lopes. A parte deste trabalho, não foram encontrados outros estudos sobre instituições locais.

Ao perceber-se a necessidade de incentivar a preservação da história das instituições escolares locais, o projeto de pesquisa passou a dedicar-se à Escola Estadual de Ensino 
Fundamental General Osório ${ }^{1}$, que se constituiu na primeira instituição de ensino pública (mantida com recursos e em espaço destinado pelo governo estadual) instalada na localidade. Sua primeira denominação foi $15^{\mathrm{a}}$ Aula Mixta, cuja responsável foi a Professora Maria Thereza Villanova Castilhos, pelo Decreto $n^{\circ} 3.042$, de 28 de outubro de 1922. Em 6 de junho de 1924, a escola, que já era denominada grupo escolar, passou a ser dirigida pela referida professora. Pelo Decreto $\mathrm{n}^{\mathrm{o}} 3.588$, de 15 de janeiro de 1926, a instituição foi elevada a colégio elementar, com a professora agora na função de diretora ${ }^{2}$.

No ano de 2016, iniciou-se o processo de digitalização do acervo fotográfico da Escola Maria Teresa Vilanova Castilhos - Escola Polivalente. A sua escolha se deu em função de que sua fundação ocorreu durante a Ditadura Militar, no bojo dos acordos entre o Ministério da Educação e a Agência Internacional de Desenvolvimento (MEC-USAID) ${ }^{3}$, os quais visavam formar mão de obra pouco onerosa, em nível de primeiro grau (equivalente ao Ensino Fundamental). Esse tipo de instituição oferecia, junto à formação propedêutica, disciplinas técnicas, as quais, em 1996, com a promulgação da Lei de Diretrizes e Bases atual, foram extintas.

A partir desse contexto, o projeto para o triênio de 2016/2017/2018 ${ }^{4}$ objetiva produzir um material impresso referente à história da instituição objeto da investigação proposta, notadamente relacionada à caracterização do acervo fotográfico da mesma, entre 1974 e 1996, respectivamente, sua fundação e a promulgação da LDB. Entende-se que o estudo da história e memória de uma instituição de educação profissional contribui para a compreensão do papel do próprio IFRS enquanto órgão formador dessa forma de ensino. Além disso, a realização de estudos sobre a região em que os campi se encontram inseridos faz parte do compromisso social do IF com esses locais.

Concomitantemente à digitalização do acervo dessa instituição, o projeto "Recuperação de dados relacionais de acervos históricos escolares e integração com sites", coordenado por servidor da área da Ciência da Computação, atua no sentido de produzir e

\footnotetext{
${ }^{1}$ O projeto de pesquisa "História das instituições educacionais e seus acervos escolares em Osório - RS" contou, a partir de 2013, com bolsistas e recursos de editais de Fomento Interno do Instituto Federal de Educação, Ciência e Tecnologia do Rio Grande do Sul, bem como com bolsistas de Fomento Externo (CNPq e FAPERGS).

${ }^{2}$ Sobre a organização do acervo fotográfico da Escola Estadual de Ensino Fundamental General Osório é possível ver: OLIVEIRA, Maria Augusta Martiarena de. Acervos escolares e história das instituições educacionais: o caso da Escola Estadual General Osório/RS. Revista Linhas, Florianópolis, v. 15, n. 28, p. 154-174, jan./jun. 2014.

3 Sobre o tema, ver Araújo (2010).

${ }^{4}$ Este projeto conta com bolsista e recursos de editais de Fomento Interno do Instituto Federal de Educação, Ciência e Tecnologia do Rio Grande do Sul, bem como com bolsista de Fomento Externo (CNPq).
} 
disponibilizar um banco de dados com as fontes coletadas, notadamente as fotográficas, por meio de um site.

Este artigo propõe-se a discorrer sobre a compreensão do acervo fotográfico como importante elemento constituinte do patrimônio histórico-educativo da instituição objeto de pesquisa e as possibilidades de estudo da cultura escolar a partir dos documentos constantes no acervo. O recorte temporal a que este estudo dedica-se é o período de 1974 a 1996 . A relevância de tal temática reside no fato de que as fotografias são materialidades integrantes do grande aspecto que compreende o patrimônio histórico-educativo. Além disso, ainda que este artigo aborde um caso local, esse estudo mostra-se como uma possibilidade para outros análogos.

\section{A ESCOLA MARIA TERESA VILANOVA CASTILHOS E SEU CONTEXTO}

Torna-se relevante destacar que, conforme Araújo (2010), durante a Ditadura Militar, as políticas educacionais foram pautadas notadamente nos acordos entre o MEC (Ministério da Educação) e USAID (United Agency for International Development) - MEC/USAID, os quais tinham como intuito adequar a educação nacional ao modo de produção capitalista. Conforme Cinca, Silva e Oliveira (2016), esses acordos tinham abrangência nacional e, entre os muitos resultados, encontrou-se a implantação das Escolas Polivalentes. Conforme Resende e Gonçalves Neto (2013), a criação desse tipo de instituição fez parte da reforma educacional estabelecida pela Lei no $5.692 / 71$, dedicada à reformulação dos ensinos de $1^{\circ}$ e $2^{\circ}$ graus, a qual tornou o último obrigatório e necessariamente profissionalizante. Conforme os autores:

\footnotetext{
No contexto internacional da Guerra Fria e do interesse norte-americano em expandir e consolidar seu poderio político e econômico aos países da América Latina, logo após o golpe de 1964, o Brasil e os EUA passaram a assinar vários acordos de cooperação entre os dois países, dentre os quais, os acordos MECUSAID para a melhoria da educação brasileira. (RESENDE; GONÇALVES NETO, 2013, p. 129).
}

Segundo Araújo (2010), a educação foi utilizada com fins ideológicos e políticos, portanto não foi levada em consideração a realidade social do país, impedindo assim qualquer possibilidade de desenvolvimento econômico das classes menos favorecidas. A implantação das Escolas Polivalentes foi possível através de financiamentos da Agência Internacional de Desenvolvimento e seguiu a proposta desse organismo internacional, que visava, notadamente, atender a demanda de mão de obra barata, assim como o atendimento das classes menos 
favorecidas. Dessa forma, ao mesmo tempo em que se formavam profissionais para atender às demandas da indústria, atendia-se de forma precária e assistencialista, as camadas populares, oferecendo-lhes uma educação profissional em nível primário. Além disso, Araújo (2010) indica que programas de estudos proporcionados e patrocinados pelos Estados Unidos para brasileiros, que depois de participarem dos referidos programas, deveriam retornar para o Brasil e desenvolver tais práticas no novo modelo de ensino do país.

Segundo Resende e Gonçalves Neto (2013):

Para que o acordo entre o MEC e a USAID pudesse ser viabilizado, a USAID
contratou quatro especialistas, que atuariam como consultores por dois anos, e que,
em conjunto com quatro educadores brasileiros, comporiam a equipe responsável
por implementar as ações previstas pelo convênio. Assim, foi estruturada a EPEM
(Equipe de Planejamento do Ensino Médio) nacional, com oito membros, para
assessorar os estados e implantar as EPEMs locais, subordinadas à nacional. O
acordo que, inicialmente, previa uma duração de dois anos - 31/03/65 a 30/07/67 -
foi sendo renovado e vigorou até 1976 e atendeu principalmente os estados do Rio
Grande do Sul, Minas Gerais, Espírito Santo, Bahia e Pernambuco. (RESENDE;
GONÇALVES NETO, 2013, p. 130).

Faz-se necessário destacar que a compreensão de Ensino Médio não se encontra relacionada à atual, a qual é oriunda da Lei de Diretrizes e Bases da Educação Nacional, promulgada em 1996 (Lei no 9394/96). Nesse sentido, as séries finais do Ensino Fundamental, anteriormente denominadas "ginásio", eram consideradas como ensino secundário e doravante denominadas de ensino médio. Além disso, salienta-se que, como mencionado pelos autores, o Rio Grande do Sul constava entre os estados que foram atendidos pela Equipe de Planejamento do Ensino Médio (EPEM). Os autores destacam, também, que a EPEM deu origem ao PREMEM (Programa de Expansão e Melhoria do Ensino Médio), o qual foi regulamentado pelo Decreto n. 63.914, de 26 de dezembro de 1968, e visava incentivar o desenvolvimento quantitativo, a transformação estrutural e o aperfeiçoamento do ensino médio.

Segundo Araújo (2010), a criação das Escolas Polivalentes encontra-se vinculada ao projeto de educação da Aliança para o Progresso, o qual se constituía em um programa de ajuda externa norte-americana, direcionado para a América Latina, lançado no início da administração de J. F. Kennedy (1961-63) e implantado nos anos subsequentes (RIBEIRO, 2006). Esse autor aponta para o fato de que o então presidente dos Estados Unidos propôs um plano de cooperação de dez anos, que objetivava fomentar o desenvolvimento econômico, social e político. O mesmo indica que a Aliança para o Progresso inseria-se numa tradição que 
remontava ao New Deal ${ }^{5}$ e aos programas do pós-guerra como o Point Four ${ }^{6}$ e o Plano Marshall $^{7}$. No sentido de efetivação dessa proposta, Araújo (2010) destaca a Reunião Extraordinária do Conselho Interamericano Econômico e Social em Nível Ministerial, realizada em Punta del Este, no Uruguai. Nessa reunião, estabeleceu-se um plano de metas para a educação, as quais deveriam ser alcançadas nos dez anos seguintes.

No bojo desses acordos, assim como em diversos municípios brasileiros, foi fundada na cidade de Osório, no Rio Grande do Sul, a Escola Estadual Maria Teresa Vilanova Castilhos - Escola Polivalente. Conforme a revista Planador: "Inaugurada no dia 14 de novembro de 1974, é a Escola Osoriense que cumpre, fiel e cabalmente, os objetivos dispostos nos primeiros artigos da Lei da Reforma do Ensino, ou seja, a sondagem de aptidões e a iniciação para o trabalho" (PLANADOR, 1975, p. 15). A matéria publicada nesse periódico de circulação local foi assinada por José Carlos Becker, Diretor do PREMEM. Nesse pequeno acerto, verifica-se a vinculação da proposta educacional proveniente das relações entre o MEC e a USAID, notadamente no que tange às aptidões e a preparação para o trabalho.

A relação entre o estabelecimento da escola na cidade de Osório e tais acordos também são evidenciadas na matéria assinada por Becker, quando o mesmo afirma: "O custo do Polivalente anda ao redor de Cr\$ $3.000 .000,00^{8}$ (três bilhões antigos), provindos de convênios entre USAID, MEC, SEC e Prefeitura Municipal” (PLANADOR, 1975, p. 15). É possível notar que a instituição dessa rede de escolas foi um empreendimento que envolveu muitos recursos e instituições diferentes, além de envolver as esferas nacional, estadual e municipal.

Conforme as informações constantes na revista Planador, a escola contava com 32 professores "especialmente treinados para este tipo de escola" (PLANADOR, 1975, p. 15). Becker destacava que o Pessoal Técnico-administrativo, segundo ele Diretor, Vice, Coordenador e Orientador, havia cursado, no mínimo, duas faculdades. Com relação aos discentes, a instituição recebia os alunos das séries finais do $1^{\circ}$ grau. Em 1975, a escola contava com 640 alunos $^{9}$.

5 O New Deal foi um plano de recuperação da economia americana implantado por Roosevelt, após a crise de 1929. Sobre o tema ver Ribeiro (2006).

6 De acordo com Ribeiro (2006), o Point Four (Ponto Quatro) foi um vasto programa de assistência técnica. O autor afirma que, no Brasil, este possibilitou a criação de uma comissão conjunta, composta por representantes brasileiros e americanos, denominada Comissão Mista Brasil- Estados Unidos - CMBEU.

7 O Plano Marshall objetivava a recuperação da economia europeia. Sobre o tema ver Ribeiro (2006).

8 Cruzeiros foi a moeda corrente no Brasil entre 1970 e 1986, antecedida pelos cruzeiros novos e seguida pelos cruzados.

9 Tal informação foi disponibilizada na matéria da Revista Planador, entretanto, é passível de confirmação. 
A inversão de recursos na construção dessa rede de escolas gerou frutos notadamente em sua estrutura física. Em Osório, a instituição contava com amplas salas de aula convencionais (salas que comportavam 40 alunos, conforme a matéria assinada por Becker e publicada na revista Planador), além de salas de aula específicas para cada disciplina técnica ofertada, uma biblioteca com vasto acervo, além de grande estrutura externa, com campo de futebol, quadras poliesportivas de concreto e areia, pista de corrida e de salto em distância. Além da estrutura física a inclusão de disciplinas técnicas no currículo (técnicas industriais, técnicas comerciais, técnicas agrícolas e técnicas domésticas), era considerada um diferencial. Conforme Becker:

\begin{abstract}
As salas especializadas (Técnicas Industriais, Agrícolas, Domésticas e Comerciais) são bem equipadas, oferecendo condições de atingir ótimo nível de ensino. - As salas de Ciências são riquíssimas em microscópios, lâminas, frascos, produtos químicos, etc. - As Técnicas Industriais possuem vários setores: Gráfica, Metais, Madeira, Cerâmica, Eletricidade, Solda, Pintura, etc. - As Técnicas Agrícolas, em sua área experimental, está usando o microtrator, corretivos e fertilizantes, desenvolvendo as seguintes atividades do setor primário: SilviCultura, Culturas Regionais, Fruticultura, Horticultura, Floricultura, Ripado, Agrostologia e Piquete. As Técnicas Domésticas abarcam atividades como Puericultura, Nutrição, Vestuário, Beleza, etc. - As Técnicas Comerciais, além de ensinamentos normais de escritórios, mantêm em atividade uma lojinha com vitrinismo, expositores, etc. (PLANADOR, 1975, p. 15).
\end{abstract}

A leitura do excerto permite vislumbrar, ao mesmo tempo, o papel das disciplinas técnicas na formação de mão de obra e a valorização da estrutura física escolar. Destaca-se que a proposta do tipo de escola em questão, como afirmado por Araújo (2010) e Resende e Gonçalves Neto (2017), era formar trabalhadores para atuar em determinados setores da economia nacional, os quais, entretanto, não se configuravam em uma mão de obra onerosa, tendo em vista sua formação apenas em $1^{\circ}$ grau.

\title{
ACERVOS FOTOGRÁFICOS COMO PATRIMÔNIO EDUCATIVO: O CASO DO ACERVO DA ESCOLA POLIVALENTE
}

Conforme Mogarro (2013), a direção de olhares pelos historiadores da educação sobre o patrimônio e o patrimônio educativo, bem como sobre modelos de cultura escolar e a materialidade da escola constitui-se em um processo iniciado no final do século XX e início do século XXI. Deve-se ter em conta que o estudo da materialidade escolar abrange uma série de objetos presentes no espaço escolar ou que remetem a esse. Como afirma a autora, as últimas décadas vivenciaram uma preocupação com a preservação do patrimônio educativo, 
nesse sentido, tais objetos outrora considerados cotidianos, ordinários, tornaram-se relevantes para o estudo da cultura escolar.

Ao levar-se em conta a relevância da preservação dessa materialidade do universo escolar, depara-se com o contexto específico da cidade de Osório, município do interior do Rio Grande do Sul, cuja preocupação com a preservação do patrimônio pouco havia aflorado até o presente momento. Ressalta-se que o caso do município do Osório, não se constitui, de todo, uma singularidade. Os municípios do interior do Brasil nem sempre contam com muitas iniciativas de preservação do patrimônio histórico-educativo, inclusive porque as capitais e cidades maiores contam com uma variedade de instituições que atuam nesse sentido.

Esse atraso em relação ao processo de preservação do patrimônio educativo de instituições escolares de cidades maiores ou mesmo de instituições com respaldo financeiro maior acarretou, no caso de muitas escolas da cidade de Osório, a perda de inúmeros objetos passíveis de guarda. Nas instituições que foram objeto de pesquisa do projeto de pesquisa, até o presente momento, encontrou-se pouca documentação e objetos que não as fotografias. Logo, concomitantemente à impossibilidade de promover a criação de um espaço de guarda no interior das próprias escolas, devido à insuficiência de recursos financeiros, as fotografias, grande maioria dos objetos encontrados, tornaram-se o foco da investigação. Pode-se dizer que essas são documentos inestimáveis que se relacionam amplamente com a história das instituições educacionais. Nesses lugares, álbuns de fotografias ou imagens avulsas constituem-se em fragmentos da memória institucional, independente da preocupação em preservá-los ou não. Entende-se que as mesmas podem ser compreendidas como patrimônio:

O patrimônio cultural, material ou imaterial está constituído por aquelas coisas, relatos ou práticas, que em um tempo histórico determinado, foram legitimadas e significadas por um grupo social, instituição ou indivíduos. Consideramos como patrimônio qualquer objeto, material ou imaterial, com capacidade de informar sobre a história da educação, seja porque serve como suporte para o registro e interpretação de dados (edifícios, mobiliário, livros, textos, vídeos, material didático, história oral, etc.), ou porque em si mesmo é significativo (por exemplo: as ilustrações originais para livros de leitura da Editorial Estrada doadas ao museu por Tomás Estrada). (LINARES; ALDEROQUI, 2013, p. 6, tradução nossa) ${ }^{10}$.

10 Texto original: El patrimonio cultural, material o inmaterial está constituido por aquellas cosas, relatos o prácticas, que en un tiempo histórico determinado, han sido legitimadas y significadas por un grupo social, institución o individuos. Consideramos como patrimonio cualquier objeto, material o inmaterial, con capacidad de informar sobre la historia de la educación, ya sea porque sirve como soporte para el registro e interpretación de datos (edificios, mobiliario, libros, textos, videos, material didáctico, historia oral, etc.), o porque en sí mismo es significativo (por ejemplo: las ilustraciones originales para libros de lectura de la Editorial Estrada donadas al museo por Tomás Estrada). 
Compreende-se, então, que as fotografias são documentos estreitamente relacionados à legitimação e significação das instituições que os produziram. Entende-se que todas as fotografias constantes no acervo podem ser consideradas fotografias escolares tendo em vista a afirmação de González Gómez e Comas Rubí (2016):

\begin{abstract}
Quando falamos de fotografia escolar, todos temos em mente uma série de imagens habituais em nosso imaginário coletivo que fazem referência ao contexto escolar no passado: no entanto, em nível prático e por não existir contexto em como definir e delimitar este termo, consideramos fotografia escolar uma grande diversidade de imagens manifestadas de formas diversas e relacionadas com o espectro escolar como denominador comum. (GONZÁLEZ GÓMEZ; COMAS RUBÍ, 2016, p. 218, tradução nossa) ${ }^{11}$.
\end{abstract}

A preservação e estudo de tais imagens permite o desenvolvimento de investigações que se dediquem ao contexto escolar osoriense. Destaca-se, ainda, que o acervo estudado foi produzido por uma determinada instituição, logo, pode-se desvelar inúmeras características da escola com base em seu acervo. Para corroborar com essa afirmação, a investigação desenvolvida por Comas Rubí e Sureda Garcia (2016), com relação às fotografias do Colégio Sant Josep Obrer, os autores entendem que as imagens institucionais publicadas, independente do suporte (digital, papel, etc.), visam à criação de uma identidade coletiva e o desenvolvimento de relações simbólicas que poderiam ser compartilhadas por todos aqueles que se sentem membros desse coletivo. Tais práticas reforçariam o sentimento de pertencimento ao grupo. Para os autores, as atividades retratadas são estereotipadas, montadas, com o intuito de desenvolver um repertório de elementos simbólicos específicos que fundamentariam um discurso identitário próprio.

As fotografias escolares, portanto, são representações que se vinculam mais à compreensão institucional sobre sua identidade do que sobre o cotidiano escolar. O seu estudo precisa partir do pressuposto de que as fotografias contam com elementos da realidade, no entanto, não são sua reprodução fiel. Torna-se relevante o que afirma Linares e Alderoqui: "Entendemos que una tarea fundamental del museo consiste en 'desnaturalizar' los fenómenos sociales, es decir 'develar' su carácter construído" (LINARES; ALDEROQUI, 2013, p.5). A necessidade de desnaturalizar tais fenômenos é relevante no sentido de analisar os documentos criados na esfera escolar ou a elas pertencentes. Desnaturalizar incide sobre o fato de lançar um olhar específico, diferenciado, que permita a compreensão de tais

11Texto original: "Cuando hablamos de fotografía escolar todos tenemos en mente una serie de imágenes habituales en nuestro imaginario colectivo que hacen referencia al contexto escolar en el pasado; sin embargo, a nivel práctico, y al no existir todavía consenso en cómo definir y delimitar este término, consideramos fotografía escolar a una gran diversidad de imágenes manifestadas de formas diversas y relacionadas con el espectro escolar como denominador común". 
documentos como construção. Esse exercício de análise e interpretação está em consonância com o que afirma Grosvenor: "Eles são sempre para um propósito, sempre em contexto. Fotografias criam eventos isolando e contendo um momento no tempo dentro de um quadro, um momento privilegiado em outras instâncias que estão perdidas" (GROSVENOR, 2010, p.154, tradução nossa) ${ }^{12}$.

Utilizando-se como base tal fundamentação, a qual nos atém para a necessidade de termos em conta o caráter de seleção das imagens, desenvolve-se desde 2016, um estudo sobre o acervo fotográfico da Escola Maria Teresa Vilanova Castilhos - Polivalente. O acesso ao acervo se deu por meio de oficialização das intenções de pesquisa, por meio de ofício endereçado à direção da escola. Atendida à solicitação, iniciou-se o processo de digitalização do acervo da mesma, o qual ocorreu sistematicamente em atividades realizadas duas vezes por semana. Como instrumento de digitalização, utilizou-se scanner de mão. As fotografias encontravam-se armazenadas em álbuns, os quais foram disponibilizados. A efetivação das atividades de digitalização ocorreu na sala dos professores, espaço destinado pela gestão da instituição. Duas bolsistas atuaram nessas atividades.

O acervo encontrava-se bem conservado, com as imagens armazenadas em álbuns, como já informado, organizadas com fotos coladas em folhas brancas com a data e a descrição do evento fotografado, dispostas em ambos os lados das folhas. A organização já existente levava em consideração os critérios cronológicos e temáticos, logo, os álbuns encontravam-se separados por ano e temas, como as festividades como aniversário da escola, desfile cívico, semana farroupilha ${ }^{13}$, entre outros. Tal organização, ainda que seja de extrema importância, gera-nos questionamentos relacionados à veracidade das informações apresentadas. Pelo estado de conservação dos álbuns e características dos mesmos (tratam-se de pastas arquivo, com espaço para armazenamentos de folhas A4 em plásticos) observa-se que a sua organização não se deu contemporaneamente à produção das fotografias, pelo menos das mais antigas.

O contexto atual da Escola Polivalente inviabiliza a organização de um museu escolar no qual as fotografias receberiam os devidos cuidados, tais como armazenamento. Tal situação é replicada na maioria das escolas da rede estadual de ensino do município de Osório. Logo, partindo-se dessa constatação, optou-se por atuar no sentido de constituir um

12 Texto original: "They are always for a purpose, always in context. Photographs create events by isolating and containing within a frame a moment in time, a moment which is privileged over other instances which are lost".

${ }^{13}$ Semana farroupilha é uma comemoração cívica do estado do Rio Grande do Sul. Refere-se à Revolução Farroupilha ou Guerra dos Farrapos (1835-1845), comemorada no dia 20 de setembro, como referência à proclamação da República Rio-Grandense. Costumeiramente, ocorre uma série de comemorações que se referem a esse movimento ocorrido durante o período regencial. 
banco de dados que possibilitaria o acesso aos acervos fotográficos das instituições escolares até então estudadas. A digitalização configurou-se, então, no meio possível de preservação do patrimônio histórico-educativo das instituições escolares estudadas.

Deve-se ter em conta que a digitalização constitui-se como um processo mais complexo que possibilita, além da preservação, o acesso e a difusão dos acervos, envolvendo ainda o processamento, o armazenamento, a distribuição e o gerenciamento do ambiente em que se encontra o acervo. De acordo com as orientações do Conselho Nacional de Arquivos: “A adoção de um processo de digitalização implica no conhecimento não só dos princípios da arquivologia, mas também das questões relacionadas à escolha e ao gerenciamento do ambiente tecnológico em que se inserem os representantes digitais." (CONARQ, 2009, p. 4).

De acordo com Cinca, Silva e Oliveira (2016), após a digitalização completa do acervo, teve início a caracterização do mesmo. Tendo em vista a vasta quantidade de fotografias, optou-se, em um primeiro momento, por elencar o recorte temporal entre a fundação da escola (1974) até a promulgação da Lei de Diretrizes e Bases da Educação Nacional - LDB (Lei 9394/96). Durante esse período foram encontradas e encontram-se em processo de catalogação 743 (setecentos e quarenta e três) fotografias. Atualmente, tais fotografias passam por um processo de organização. Para sua posterior disponibilização através de banco de dados de acesso pela web, as imagens são organizadas com base em categorias:

Quadro 1: Categorias para caracterização do acervo fotográfico da Escola Polivalente.

\begin{tabular}{|c|c|c|}
\hline \multirow[t]{2}{*}{ Espaços } & Gerais & Imagens do prédio \\
\hline & Singulares & $\begin{array}{l}\text { Salas de aula, horta, salas das } \\
\text { disciplinas técnicas. }\end{array}$ \\
\hline \multirow[t]{3}{*}{ Protagonistas } & Docentes/Corpo diretivo & \\
\hline & Discentes & \\
\hline & Relacionados & Autoridades, visitantes \\
\hline \multirow[t]{2}{*}{ Atividades } & Formais & $\begin{array}{l}\text { Atreladas ao currículo, } \\
\text { atividades de sala de aula, } \\
\text { práticas de disciplinas técnicas. }\end{array}$ \\
\hline & Não formais & $\begin{array}{l}\text { Atividades extracurriculares, } \\
\text { comemorações, festividades, } \\
\text { desfiles cívicos, etc. }\end{array}$ \\
\hline
\end{tabular}

Fonte: Quadro elaborado pela autora em colaboração com os bolsistas, tendo como referência Almeida-Aguiar e Alemán-Ramos (2017). 
As categorias gerais são divididas em temáticas e palavras-chave, as quais visam possibilitar a pesquisa e a localização de fotografias no acervo. Destaca-se que essa identificação ainda está em andamento. Além de disponibilizá-lo de forma on-line, realiza-se um trabalho de análise das fotografias constantes no acervo, o qual pretende gerar uma série de estudos de diferentes aspectos da cultura escolar. Alguns desses estudos já foram iniciados, tais como: contexto de fundação da escola; o espaço das disciplinas técnicas, sua proposta vinculada aos acordos com organismos internacionais e o espaço escolar a elas destinado; o papel das comemorações cívicas para a Escola Polivalente durante o regime militar e no período imediatamente posterior; docentes e alunos: papéis sociais, gênero e educação profissional.

\section{CONSIDERAÇÕES FINAIS}

Preservar o patrimônio histórico-educativo consiste em uma tarefe deveras importante no sentido de resguardar a história e a memória da educação e das instituições escolares. $\mathrm{O}$ cuidado com esses bens materiais e imateriais que constituem o patrimônio educativo nem sempre foi uma preocupação de pesquisadores e autoridades. Entretanto, as últimas décadas foram marcadas por iniciativas no sentido de valorização do patrimônio educativo.

A amplitude da compreensão do significado de patrimônio educativo permite o entendimento de que as fotografias escolares são objetos que integram essa materialidade escolar. Deve-se entendê-las como recortes bidimensionais, produzidos por uma determinada instituição, que vislumbra nesses documentos o fortalecimento dos laços identitários da própria comunidade escolar. A instituição seleciona o que fotografar e o que perpetuar. Nesse sentido, as fotografias como patrimônio educativo configuram-se em excelente documento de estudo, resguardando-se os cuidados que os pesquisadores precisam ater-se com relação às suas fontes de investigação.

Com relação ao estudo da Escola Maria Teresa Vilanova Castilhos - Polivalente, bem como de suas homônimas, é extremamente relevante, tendo em vista que sua fundação ocorreu em um contexto específico (Ditadura Militar, acordos MEC-USAID), nesse sentido, o acervo fotográfico da referida instituição constitui-se em elemento importante para o estudo de um determinado contexto escolar marcado pelo regime militar, bem como dos efeitos que o final do período autoritário teve na proposta educacional dessa escola.

Sobre a conservação do acervo, ainda que a constituição de um museu escolar fosse o passo mais adequado no sentido de preservar a história das instituições estudadas, 
notadamente da que atualmente é objeto de pesquisa, a Escola Polivalente, as questões financeiras sobrepõem-se e a digitalização e disponibilização on-line configuraram-se na melhor forma de efetivar a preservação da memória dessas escolas. A digitalização é uma técnica que permite a preservação dos objetos em suporte de papel, mesmo depois de seu desaparecimento. Além disso, com a criação de documentos digitais, viabiliza-se o acesso a pesquisadores, sem o desgaste do objeto original.

A organização do acervo com base em categorias, além de facilitar a sua disponibilização on-line, faz-se necessária no sentido de indicar possíveis temas para estudos da cultura escolar. O acervo contém fotografias de práticas escolares e do prédio da instituição. As imagens que se referem ao último foram realizadas na parte externa do mesmo, retratando notadamente a fachada e o pátio interno. As fotografias de práticas escolares referem-se especialmente às comemorações cívicas ou não, tais como Sete de Setembro, Semana da Pátria, festas juninas, aniversário da escola e gincanas. Há poucas fotografias que objetivam retratar docentes e discentes; estes, em geral são retratados ao realizarem atividades escolares. Como foi mencionado, iniciou-se estudos sobre o contexto de fundação da escola; a estrutura física para atender as disciplinas técnicas e a sua vinculação aos acordos com organismos internacionais; os papéis de gênero a partir dessas disciplinas; finalidades das comemorações cívicas para a Escola Polivalente durante o regime militar e no período imediatamente posterior. Dessa forma, espera-se que, além de preservar a história e a memória da Escola Polivalente, possa-se contribuir para o estudo da cultura escolar.

\section{REFERÊNCIAS}

ALMEIDA-AGUIAR, Antonio S.; ALEMÁN-RAMOS, Pedro F. El Archivo de Fotografía de Canarias: fuente para el estúdio de la educación. In: XIX COLOQUIO HISTORIA DE LA EDUCACIÓN: imágenes, discursos y textos en Historia de la Educación. Retos metodológicos. Anais... Madri (El Escorial), 2017, p. 55-58.

ARAÚJO, José Alfredo de. A USAID, o regime militar e a implantação das escolas polivalentes no Brasil. Revista de Epistemologia y Ciencias Humanas, Rosário - Argentina, n. 2, 11p., 2010.

BRASIL. Lei $\mathbf{n}^{\mathbf{0}}$ 9.394/96, de 20 de dezembro de 1996. Disponível em https://www2.senado.leg.br/bdsf/bitstream/handle/id/70320/65.pdf. Acesso em: 14 de nov. de 2017.

Decreto 63.914/1968. Provê sobre o Programa de Expansão e Melhoria do Ensino Médio (PREMEM) e dá outras providências. Disponível em : http://www2.camara.leg.br/legin/fed/decret/1960-1969/decreto-63914-26-dezembro-1968405261-publicacaooriginal-1-pe.html. Acesso em : 14 de nov. de 2017. 
CINCA, Karen Aires da Silva; SILVA, Taís Silva da; OLIVEIRA, Maria Augusta Martiarena de. Escola Polivalente: a digitalização de acervo fotográfico como forma de preservação de sua história. In: $22^{\circ}$ ENCONTRO DA ASSOCIAÇÃO SUL-RIO-GRANDENSE DE PESQUISADORES EM HISTORIA DA EDUCAÇÃO. Anais... Bagé, RS: UNIPAMPA, 2016, p. 749-756.

COMAS RUBÍ, Francisca; SUREDA GARCIA, Bernat. Album photographique scolaire, histoire et configuration de l'identité des établissements scolaires: le cas du collège Sant Josep Obrer de Palma. Encounters in Theory and History of Education, [S.1.], v. 17, p. 119-140, nov. 2016.2 Disponível em: $<$ https://ojs.library.queensu.ca/index.php/encounters/article/view/6302>. Acesso em: 16 out. 2017.

CONSELHO NACIONAL DE ARQUIVOS, CONARQ. Recomendações para Digitalização de Documentos Arquivísticos. 2009.

GONZÁLEZ GÓMEZ, Sara; COMAS RUBÍ, Francisca. Fotografía y construcción de la memoria escolar. History of education \& children literature, v. XI, n. 1, p. 215-236, 2016.

GROSVENOR, Ian. The School album: issues, histories and inequalities. Educacio I Historia. Revista d'Historia de l'Educacio, 15, p. 149-64, jun. 2010.

LINARES, Maria Cristina, ALDEROQUI, Silvia. El Museo de las Escuelas: una década de hacer museo. Historia de la Educación. Anuario, Argentina, v. 14, n. 1, set. 2013. Disponível em: <http://ppct.caicyt.gov.ar/index.php/anuario/article/view/3115>. Acesso em: 16 out. 2017.

MOGARRO, Maria João. Património educativo e modelos de cultura escolar na Historia da Educação em Portugal. Cuestiones Pedagógicas, 22, p. 67-102, 2012/2013.

OLIVEIRA, Maria Augusta Martiarena de. Acervos escolares e história das instituições educacionais: o caso da Escola Estadual General Osório/RS. Revista Linhas. Florianópolis, v. 15, n. 28, p. 154-174, jan./jun. 2014.

PLANADOR. 16 de agosto de 1975, ano $\mathrm{I}, \mathrm{n}^{\circ} 1$.

RESENDE, Luciana Araujo Valle de; GONÇALVES NETO, Wenceslau. Os colégios polivalentes em Minas Gerais: a experiência da escola estadual Guiomar de Freitas Costa (Uberlândia, 1971-1980). Revista de Educação Pública, [S.1.], v. 22, n. 48, p. 127-145, jun. $2013 . \quad$ Disponível em: $<$ http://periodicoscientificos.ufmt.br/ojs/index.php/educacaopublica/article/view/851/652>. Acesso em: 18 out. 2017.

RIBEIRO, Ricardo Allagio. A teoria da modernização, a aliança para o progresso e as relações Brasil - Estados Unidos. Perspectivas, São Paulo, 30, p. 151-175, 2006. 